\author{
L. Latka ${ }^{1, *}$, P. Biskup ${ }^{1,2}$ \\ 1 Wrockaw University of Science and Technology, Faculty of Mechanical Engineering, \\ Wrocław, Poland \\ ${ }^{2}$ Legnica Cooper Smelter and Refinery, Legnica, Poland \\ *leszek.latka@pwr.edu.pl
}

\title{
DEVELOPMENT IN PTA SURFACE MODIFICATIONS - A REVIEW
}

\begin{abstract}
Surface modification is one of the most intensively studied issue of technology, which is related to the almost all branches of industry. Since more than 100 years the huge number of methods has been developed and are still in growth. On this field the plasma transferred arc (PTA) hardfacing and surfacing is one of the most frequently used group of the method. The development of this method is going in three ways: (i) modification of the classic technique and the equipment, (ii) development in new materials, especially with the nanometric size and (iii) replacement dangerous materials (e.g. high cobalt alloys). In the current article the state of the art as well as the development directions of the plasma hardfacing issues are described.
\end{abstract}

Keywords: plasma hardfacing; surfacing; wear resistance; erosion resistance; corrosion resistance

\section{INTRODUCTION}

Surface engineering is a huge branch of science and technology. It concerns modification of existing surfaces and/or building a new coating. The main aim of this processes is improving the life time of machines components [1]. It should be stressed, that almost all above mentioned methods could be used for both, create a new elements and rebuilt of worn surfaces or part of the elements.

An appropriate selection of the surface modification method is very complicated issue. It depends not only on operating conditions, base material and cost. Additional it is linked to the large variety of the feeding materials (metals, ceramic, cermet, etc.). The estimated number of materials used in surface engineering is about 70000. Furthermore, another factor in the proper choice is the huge number of the technological processes. Total number of the methods of surface modification is around 1000 [2]. For this reason the selection process should be systematic and includes following aspects: functional characteristic of the element and the requirements of the work environment, technical issues, economical aspects and many others details [1,2]. Different groups of the methods of the surface layers manufacturing are presented in Fig. 1. 


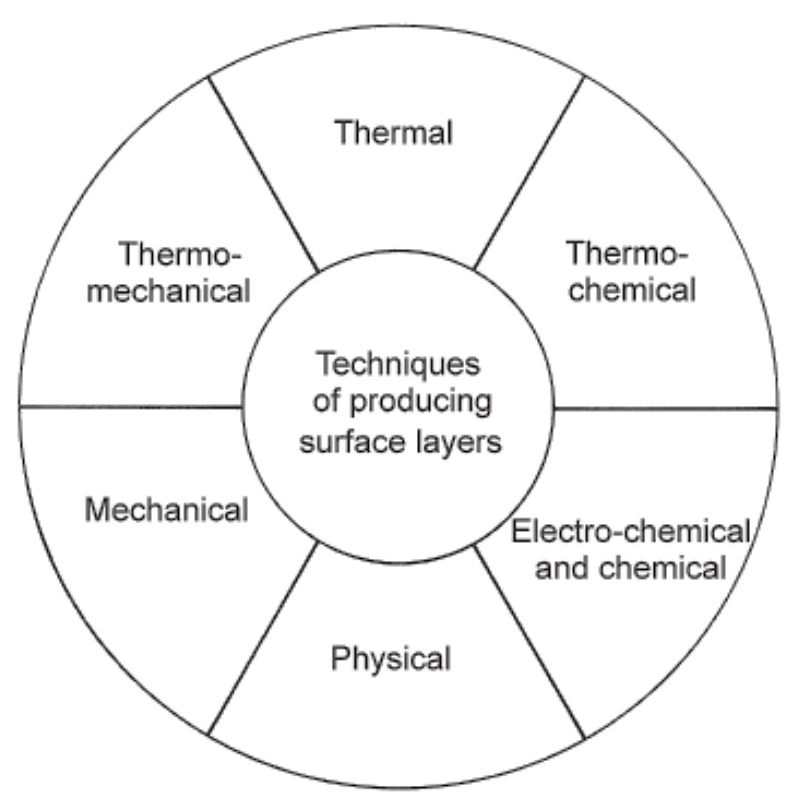

Fig. 1. Types of surface layers manufacturing techniques [1]

In this review only welding technologies will be briefly discussed. Among them plasma hardfacing will be described in details. On the field of welding, there are two groups of coating deposition methods: (i) thermal spraying and (ii) hardfacing. The fundamental difference between spraying and hardfacing technique is melting of the substrate. In case of thermal spraying methods it is not occur, what results in lower adhesion caused by only mechanical contact between coating and substrate. Another factor is the presence of defects, such pores and cracks, which could be a weak point in case of wear and corrosion resistance [3]. Nevertheless, thermal spray coatings are wide used in many branches of the industry. The flame [4,5], arc [6,7], plasma [8,9], high velocity oxy-fuel (HVOF) [10,11] spraying method, as well as cold gas spray [12,13] allow to obtain wear, corrosion and erosion resistance coatings. On the field of hardfacing technologies, there are conventional methods, including manual metal arc, gas metal arc, gas tungsten arc and submerged arc also existed [14-17]. On the other hand, there are high-energy density methods, such laser beam [18,19], electron beam $[20,21]$ and plasma arc, which are widely used in surfacing layers manufacturing.

In general, hardfacing deals with technology of additional overlays manufacturing, which prevent the substrate against wear, erosion, corrosion, high temperature etc. However it is also used in order to restore element dimensions, which were damage by means of wear [22].

\section{PLASMA ARC HARDFACING FUNDAMENTALS}

The beginnings of the plasma transferred arc (PTA) hardfacing go back to the 1960s, when the process of plasma welding was adopted for surface modification by the overlays production [23]. Generally, the PTA is a development of gas tungsten arc (GTA) method. The plasma arc is constricted and tungsten electrode is placed inside the torch. Due to the higher ionization of plasma arc it is possible to more precise parameters and results (dilution and penetration) steering [24]. In Fig. 2 the scheme of PTA torch as well as process principle are presented. As it could be observed, the filler material (in form of powder) is injected to the 
plasma arc in the shielding gas, which prevent melting particles against the oxidation. It results in very pure, from metallurgical point of view, deposits and its high quality [25].

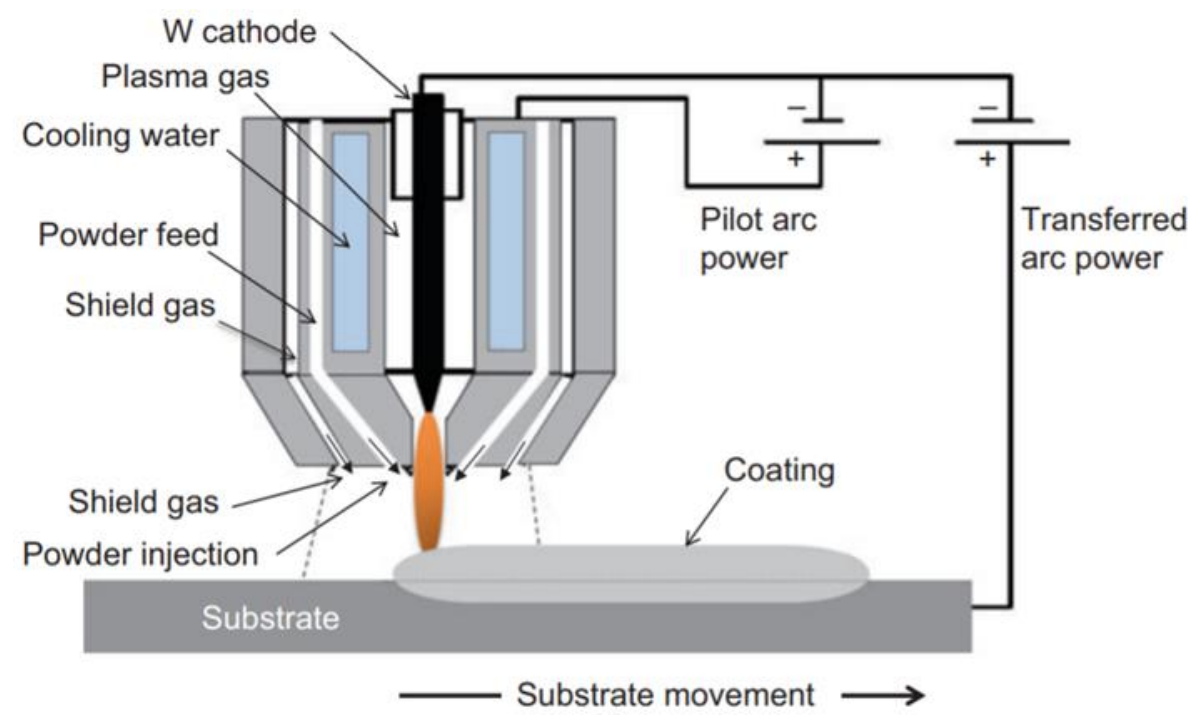

Fig. 2. Scheme of PTA torch and hardfacing process [26]

Plasma hardfacing is a technique, which has many advantages compared to other arc methods, such as high melting efficiency, high stability of the energy flux and improved adhesion to the overlaid substrate [27]. Moreover, the process costs are lower and its efficiency is higher in compare PTA with others high density of energy methods (laser- and electron beam) $[28,29]$. Despite the fact, that filler material for PTA hardfacing could has a form of wire, in this method powder consumables are mainly used. This form is easier to feed and requires lower value of heat input in order to melt it to form a weld overlay. The scheme of wire PTA hardfacing method is presented in Fig. 3.

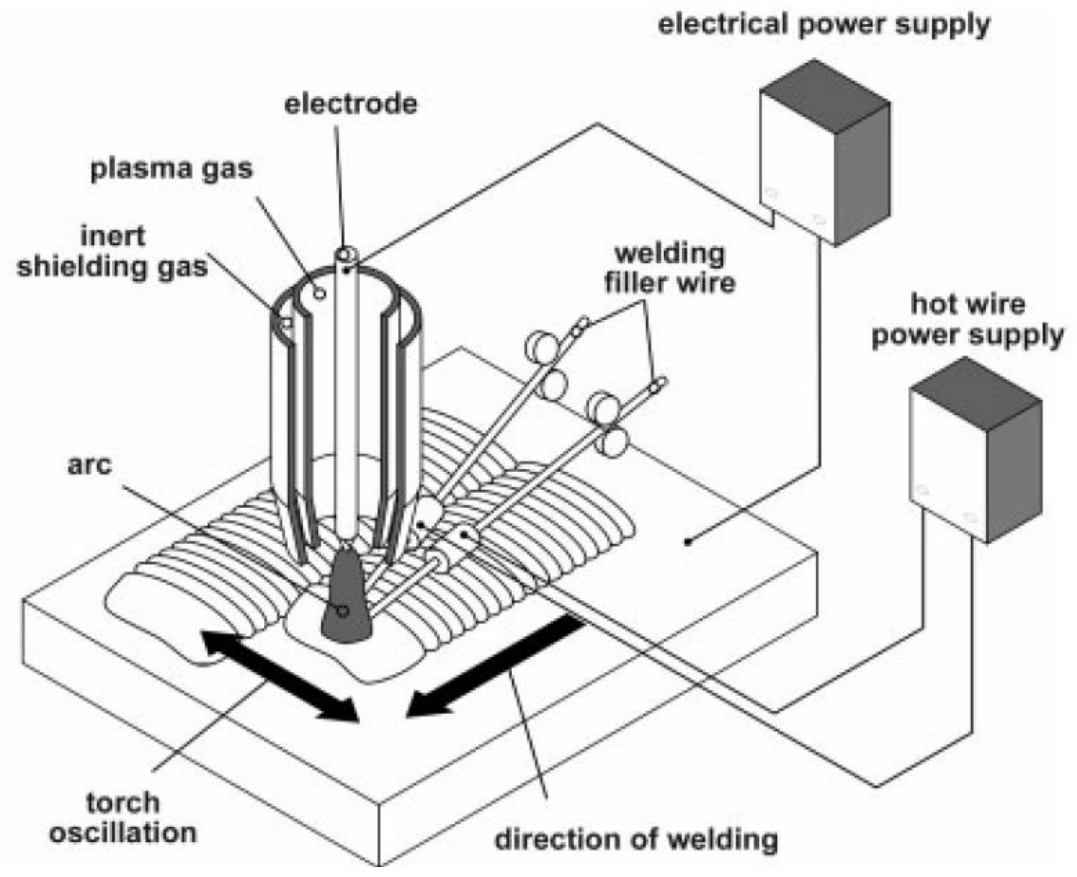

Fig. 3. Scheme of wire PTA hardfacing [2] 
Powders, as a form of feeding material, give wide flexibility it terms to manufacture overlays with desired composition, including composite coatings. On the other hand, there are many types of materials in the form of powder wires, which gives the opportunity of the relatively wide selection. Nevertheless, from a technological point of view, there are some difficulties to produce wires with diameter $1.6 \mathrm{~mm}$ and larger, which is especially important with high efficiency methods and applications [30]. Very interesting, from hard industry application point of view, are metal matrix composites (MMCs), which combine wear and erosion resistance (carbides, nitrides, borides) with corrosion resistance and high operating temperatures (Ni- and Co-based alloys) [28,31-33]. The major advantages as well as disadvantages of PTA hardfacing method in compare to the conventional arc processes are collected in Table 1.

Table 1. Main advantages and disadvantages of PTA hardfacing method [26,34]

\begin{tabular}{ll}
\hline \multicolumn{1}{c}{ Advantages } & \multicolumn{1}{c}{ Disadvantages } \\
\hline $\begin{array}{l}\text { low dilution - it could be about 5\%, so it means } \\
\text { that there is very small quantity of base material } \\
\text { in the weld metal }\end{array}$ & $\begin{array}{l}\text { metallic substrate is required in order to plasma } \\
\text { arc ignition between substrate and electrode in } \\
\text { comparison with thermal spraying methods }\end{array}$ \\
$\begin{array}{l}\text { fine microstructure of deposit as well as smooth } \\
\text { surface after the process }\end{array}$ & $\begin{array}{l}\text { the vertical surfaces are very difficult to deposit } \\
\text { because of gravity } \\
\text { poor adaptation to complex shapes }\end{array}$ \\
high powder feed rates & $\begin{array}{l}\text { relatively high values of residual stresses } \\
\text { metallurgical compatibility between substrate and } \\
\text { high deposition efficiency (more than 95\%) }\end{array}$ \\
low porosity of deposits & \\
strong adhesion by metallurgical bonding & \\
between substrate and coating & \\
low heat affected zone & \\
saving the cost because of low dilution, the layer \\
could be thinner and the surface of the substrate \\
does not require grooving
\end{tabular}

The overlays quality and properties are strongly dependent on the hardfacing material powder but also on process parameters. The fundamental ones are as follow: the pilot and transferred arc current, plasma gas, carrier gas and shield gas flow rate, powder feed rate, hardfacing distance and surfacing velocity and plasma torch oscillation. There is a wide literature dedicated of the above mentioned parameters influence on the overlays $[26,30,35]$.

In general, three production levels of PTA hardfacing method could be listed, depending on dimensions of the coated element: (i) micro-PTA - for small components or with complex shapes, (ii) regular PTA and (iii) high-power PTA - for rapid deposition or hardfacing large 
components surface [26]. The summary of the fundamental conditions for each levels are collected in Table 2 .

Table 2. Fundamental differences between various scales of PTA method [26]

\begin{tabular}{lccc}
\hline \multicolumn{1}{c}{ Operating parameter } & micro-PTA & regular PTA & high-power PTA \\
\hline pilot arc current (A) & - & $50-100$ & $50-100$ \\
pilot arc voltage (V) & - & 40 & 40 \\
transferred arc current (A) & $5-50$ & $100-300$ & $200-400$ \\
transferred arc voltage (V) & 20 & 40 & 50 \\
powder feed rate $(\mathrm{kg} / \mathrm{h})$ & $0.1-2$ & $2-10$ & $10-20$ \\
\hline
\end{tabular}

Because of many PTA hardfacing advantages, as well as wide range of filler materials, the are a huge number of industrial applications of such overlays. The main ones are connected with: wear resistance [36,37], corrosion resistance [38] and abrasive resistance [39]. Additional applications are connected with e.g. high temperature wear resistance [40] or like a self-lubricating surfaces [41]. In general, the industrial branches, where PTA hardfacing is used are as follow: ore mining, oil drilling, power generation, steel manufacturing, petrochemical, marine, etc. [42-44]. Some typical examples of applications are: valve and valve seats, bucket of wheel excavator, tools for metals forming, agriculture machines elements, compressor blades of aircraft engines, aluminum die-casting metal mold [45].

\section{PLASMA ARC HARDFACING PROCESS MODELING}

Numerical analysis and modeling is recently more and more important in all technological branches [46-48] because it allows in better understanding the processes and helps in selection of fundamental properties [49-51]. On the other hand, on the field of PTA hardfacing, the numerical modeling deal with rather to residual stresses determination or HAZ prediction. The physical phenomena of plasma jet are based on physicist researches.

From a physical point of view many studies deals with interactions between plasma and electrodes. The investigations are carried out in order to energy distribution estimation in plasma arc [52] or to predict plasma temperature profiles, which is very important for next estimation of plasma velocities [53]. The interaction between anodes [54] and cathodes [55] are also often investigated by numerical simulation.

In the literature there is very small articles about typical numerical modeling of the PTA hardfacing process. One of the few examples is [56], in which the plasma surfacing has been modeled. The main reason was big number of process parameters and the need to reduce the carried out experiments. On the other hand, the PTA method is very complex process, so the comprehensive approach includes many factors and makes numerical calculations extremely complicated.

Another example of mathematical modeling application in PTA process is prediction of the overlay geometry [57]. In this paper the analysis of variance (ANOVA) combined with response surface methodology (RSM) are used in order to describe the detailed influence of fundamental parameters on the weld overlay geometry [57]. The generic theoretical model 
and finite element simulation is also used for modeling and prediction dilution, especially for micro-PTA processes [58].

In practice, the numerical studies are used for determine the residual stresses and distortion field, as well as temperature distribution during the process [59,60]. In these examples, the finite elements analysis was applied to estimate stresses distribution in order to optimize the overlays thickness and process parameters. After hardfacing, the non-destructive ultrasound and X-ray diffraction methods were used to validate numerical analysis. In both cases, the agreement numerical and experimental results was in a good level $[59,60]$.

Recently, the multi-layer PTA hardfacing is more popular and in order to understand the complex phenomena occurred during this process also the numerical analysis is required [61].

\section{MODIFICATIONS OF THE PLASMA ARC HARDFACING}

Since 1960s, when the PTA hardfacing was invented, many modifications of the conventional process were developed. One group has been connected with process fundamentals and new techniques. Another one is linked to the new materials issue, especially in nanoscale reinforced additions. In this review the most frequently used modifications will be briefly described.

\section{Modification of powder feeding}

Small powder particles could be overheated in plasma jet. It is an undesirable phenomenon, especially for hard phases (e.g. carbides), because they could be dissolved and results in decreasing of the wear resistance. Proposed solution assumed modification of powder feeding place, as follow: (i) into the fringes of plasma arc [62] or through a special extended tubes directly to the weld pool [63]. The powder could be also feed outside the plasma handle. The first way is to feed it before plasma arc, which results in lower dilution. The other way is to feed after plasma arc, which results in high penetration depth and smooth face of the weld overlay $[45,64]$.

\section{Nitriding of weld overlays}

Modifications of the conventional process are invented in order to improve manufactured overlays. In case of nitriding, the main aim is increasing the hardness, which should results in better wear resistance. The classic PTA hardfacing is made under the nitrogen atmosphere. It was observed, that higher concentration on nitrogen in plasma gases mixture results in some instabilities of the arc. Moreover the adhesion on the edges was lower, as well as the life time of electrode. On the other hand, small quantity of nitrogen results in significantly improvement of wear resistance [65,66]. Another approach was proposed by Wang et al. [67], who deposited composite TiN/Ni weld overlays. In the microstructure of produced overlays TiN and $\mathrm{Al}_{2} \mathrm{~N}_{3}$ phases were uniformly distributed. The hardfacing layers have significantly higher hardness and lower friction coefficient as well as improve corrosion resistance [67].

\section{Modulation of process parameters}

The main parameters, which are modulated are: arc current and plasma gas flow rate. In case of arc current the first works were made by Shubert [68]. Pulse current allows to create 
the weld pool, which solidify in very short time. It results in fine grain microstructure of deposited overlays and consequently, better properties. The lower heat input also promoted lower dilution as well as lower distortion of the hardfaced element [24,69,70].

Pulsation of the plasma gas flow was examined by Ebert et al. [71] as a possibility of the more uniform distribution of the reinforcing tungsten carbides particles in the cobalt-based matrix. It results in wear resistance improvement [71].

\section{Hardfacing with negative workpiece polarity}

In recent years the light metals (manly aluminum and magnesium ones) and its alloys are more and more frequently used in wide industry applications. In case of aluminum, its mechanical properties should be reinforced, but for magnesium alloys also the corrosion resistance is poor and need improvement. Moreover, these materials have a low melting point and high thermal conductivity, which require low level of heat input during hardfacing [2]. Reversing polarity, when the workpiece is a cathode results in lower heat transfer. Moreover, additional advantage is cathodic arc de-oxidation, which is necessary to remove oxide layers from the Al- and Mg-based surfaces. This phenomenon is commonly used with GTA welding of above mentioned materials. With negative polarity authors of [72] obtained better wear resistance because of uniformly distribution of hard phase in aluminum surface, alloying base material with deposited one and hard phases creation. Another example of negative polarity PTA hardfacing could be found in [73]. Authors used aluminum alloy as a matrix for hard phases, fused tungsten carbide and TiC. After deposition and tribological investigations the results of abrasion and adhesion wear rates were better, than for stellite 6 deposited on steel [73].

\section{Other process modifications}

As it was mentioned above, one of the PTA limitation is complex shape of the workpiece. In order to rebuilt the worn components, the novel method PTA combined with tape casting was applied [74]. The surface was coated by metallic slurry, then was heat treated for better electrical conductivity and finally was treated by plasma arc. The process efficiency is much lower, than conventional PTA (about 50\%), but allows to obtain uniform overlays up to 0.6 $\mathrm{mm}$ in thickness [74].

Another modification was proposed by researches from SNMI (Avignon, France) [75]. They developed a new plasma torch with high constricted nozzle, which results in improvement of current and energy densities. It allows to extremely increase movement velocity. In such conditions, deposited overlays have very low dilution, fine microstructure and higher hardness [75].

\section{Materials modifications - nanoparticles and nanophases}

Development and applications of nanomaterials is present in all manufacturing technologies. On the field of hardfacing the main advantages of such materials are connected with improvement of mechanical and tribological properties in compare to their conventional counterparts. In general, there are two methods of improvement the PTA overlays in "nanoway": (i) metallurgical nanophases creation and (ii) nanoparticles addition.

From a metallurgical point of view, the specific variations of the elements in alloy makes it possible to solidify with common cooling rate as a form of nanostructured carbides and borides. Very important are also fundamental process parameters, which strongly influence on 
the heat input value. Moreover, for overlays deposited from hard metals in soft matrix, improvement of tribological properties is connected with strengthening of the binder phase. It could be done by nano-grain reinforcement $[76,77]$. The results obtained in referenced articles are very promising. For new $\mathrm{CrVFeCoB}$-alloy Authors got more than 2 times higher hardness and around 7 times lower wear rate in compare to the standard stellite 6 overlays [76]. Other paper deals with new WC-based alloys (W-C-Fe-Cr-Si), which have a relatively low-metling point and unique properties. As in comparable with conventional WC-Co their wear resistance is at the same level with simultaneous lower hardness [77].

Another method for PTA hardfacing overlays reinforce is an addition of nanoparticles to the feed material. Authors of [78] doped Ni-based powder by TiN and AlTiN nanoparticles and then deposited the overlays and investigated them. The results clearly showed nanoparticles reinforcement phenomenon. Improved coatings were characterized by higher wear resistance and lower friction coefficient. Moreover, based on $\mathrm{H}$ to $\mathrm{E}$ ratios (resistance of the material to elastic deformation, correlation with abrasive and erosive wear, evaluation the ability of material to dissipate energy at plastic deformation during loading) it is clear confirmed, especially for overlays with AlTiN addition, that nanoparticles strongly reinforced the Ni-based overlay [78]. One more example of nanoparticles doping a conventional feeding material is [79]. In this paper Authors added nano $\mathrm{Al}_{2} \mathrm{O}_{3}$ to the Ni-based alloy. The results in wear resistance was almost 2 times better for the nano-reinforced overlay. It was a result of forming stacking faults and dislocation cell walls by nano $\mathrm{Al}_{2} \mathrm{O}_{3}$ addition [79].

\section{Additive manufacturing by PTA}

Nowadays, the additive manufacturing is very promised technology, which is used in wide range in industry. It could be applied for fabrication and/or repair components. For PTA method the main advantage is lower heat input and precise control of feeding material. Moreover, by PTA additive manufacturing is possible to produce new elements with complex shapes, which is cross the limits of conventional PTA hardfacing. The scheme of wall building by modify PTA additive manufacturing is presented in Fig. 4a. Very important is to obtain the effective wall are as big as possible, which is connected with proper selection of the process parameters [80]. An example of produced wall of Ni-based alloy is presented in Fig. 4b.

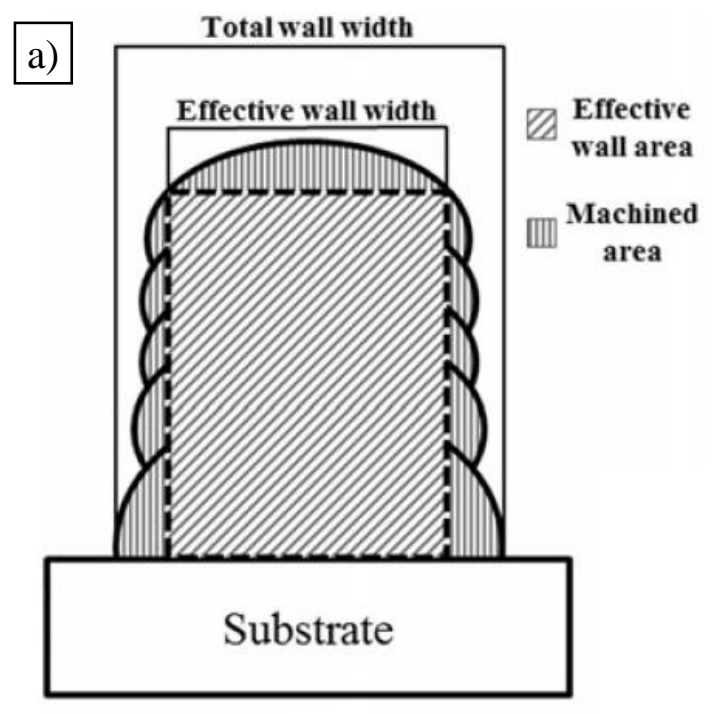

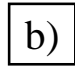

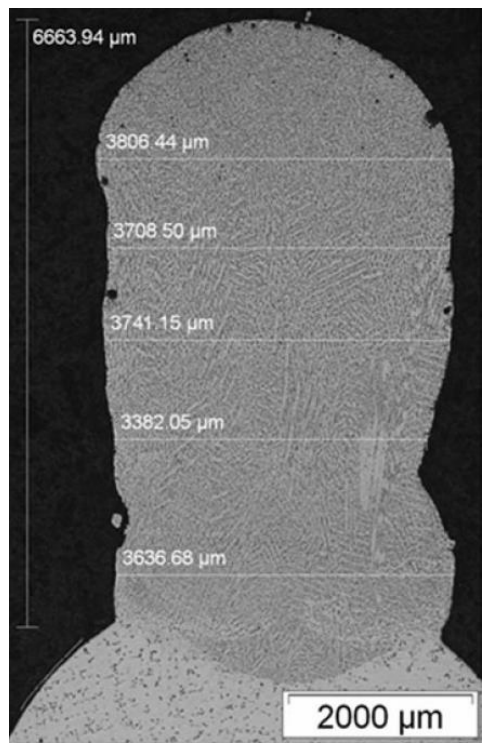

Fig. 4. Scheme of PTA additive manufacturing, with the effective wall area (a) and Ni-based alloy wall produced by PTA method (b) [80] 
Among others popular methods of additive manufacturing, like selective laser sintering (SLS), selective laser melting (SLM) and electron beam melting (EBM), the PTA technique has many advantages. It does not required such pure powders, the building rate is higher and there is no necessity of using vacuum conditions, which leads to important reduce of the production costs [81]. The new method called 3D plasma metal deposition (3DPMD) is used for aviation industry for building elements from titanium. An example pure titanium block produced by 3DPMD is presented in Fig. 5.

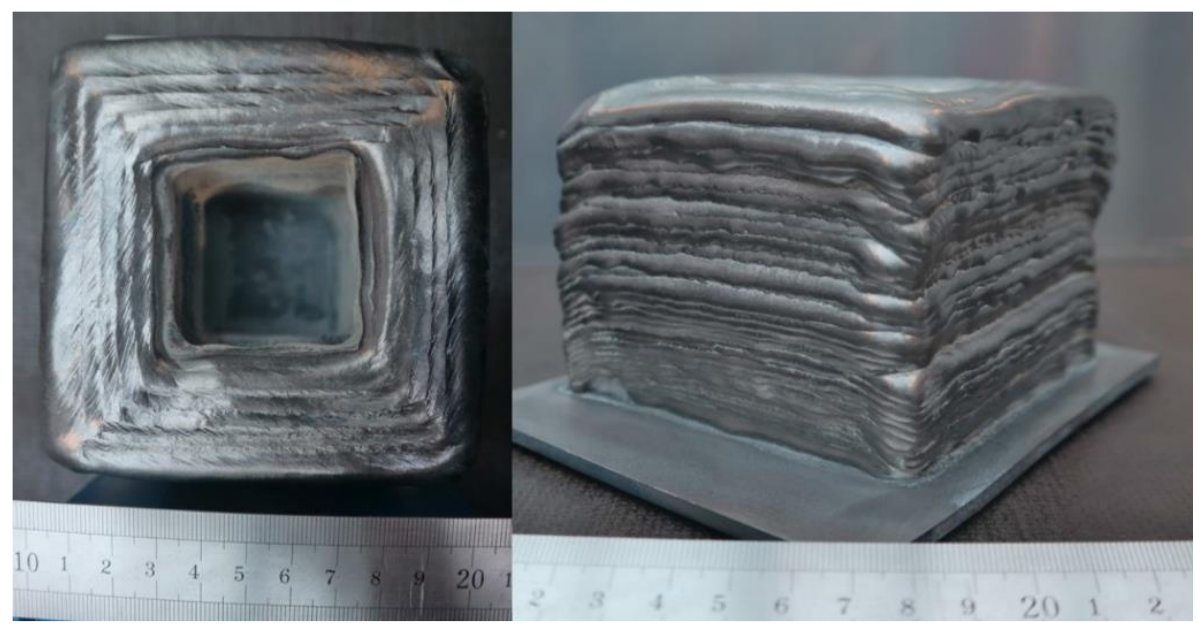

Fig. 5. View of pure titanium block produced by 3DPMD [81]

Generally, the main types of material used by plasma transferred arc - additive manufacturing (PTA-AM) are Ni-based alloys (Inconel, Hastelloy). More details about the process parameters and quality of the elements could be found in [82,83]. Moreover, for very precise applications, the micro-PTA additive manufacturing technology is used. The idea was developed for low-cost and high-efficiency method for repair and remanufacturing of the broken dies and molds [84].

\section{SUMMARY}

The plasma transferred arc hardfacing is a method of deposition manufacturing, which allows to obtain high quality overlays, with good or even excellent functional properties. Additional advantages of PTA process are connected with huge amount of filler material types (especially for powders), lower cost and higher efficiency in comparable to the others high-energy methods (a beam ones) [2,26].

Depending on the specific application, there are many process modifications, including micro-PTA [85] or high-energy PTA [86]. In order to improve functional properties (mechanical and tribological ones) many investigations were carried out [87-89]. Another method of the reinforcement deposited overlays the conventional feeding materials are modified by nano-phases creation [90] or by nanoparticles doping [91].

On the other hand, the major disadvantages are limited ability to produce deposits on complex shapes and high level of emerging residual stresses. Moreover, very important is ensuring of the metallurgical compatibility between substrate and overlay [26].

Nevertheless, there are a huge number of investigations, which provide continuous develop in new materials and its treatment, new intermetallic phases manufacturing or even 
new torch and generation of the set-up. The main trends are very clear, from an industrial application point of view, it should be better and (as it will be possible) also cheaper than existing materials and technology.

To summarize, in this literature review could be seen some deficiencies. There is only few information about functionally graded overlays. Moreover, in the industrial applications the overlays often meet a complex conditions, in which the different wear types operate at the same time, as well as corrosion with salts or acids and high temperature. It is an area for deeper investigations, which will included a complex resistance for different operating conditions, dedicated to various branches of the industry.

\section{REFERENCES}

1. Burakowski T., Wierzchoń T., Surface engineering of metals - principles, equipment, technologies, CRC Press (1999).

2. Bach F.W., Mohwald K., Laarmann A., Wenz T., Modern surface technology, Wiley-VCH, Verlag GmbH, (2004).

3. Pawłowski L., The science and engineering of thermal spray coatings, $2^{\text {nd }}$ ed., Wiley, Chichester, England, (2008).

4. Kobayashi T., Maruyama T., Kano M., Characterization of pure aluminum and zinc sprayed coatings produced by flame spraying, Materials Transactions 44 (2003) 2711-2717.

5. Czupryński A., Flame spraying of aluminum coatings reinforced with particles of carbonaceous materials as an alternative for laser cladding technologies, Materials 12 (2019) 3467.

6. Gedzevicius I., Valiulis A.V., Analysis of wire arc spraying process variables on coatings properties, Journal of Materials Processing Technology, 175 (2006) 206-211.

7. Chmielewski T., Siwek P., Chmielewski M., Piątkowska A., Grabias A., Golański D., Structure and selected properties of arc sprayed coatings containing in-situ fabricated Fe-Al intermetallic phases, Metals 8 (2018) 1059.

8. Karger M., Vassen R., Stoever D., Atmospheric plasma sprayed thermal barrier coatings with high segmentation crack densities: Spraying process, microstructure and thermal cycling behaviour, Surface and Coatings Technology, 206 (2011) 16-23.

9. Łatka L., Szala M., Michalak M., Pałka T., Impact of atmospheric plasma spray parameters on cavitation erosion resistance of Al2O3-13\% TiO2 coatings, Acta Physica Polonica A, 136 (2019) 342-347.

10. Poirier D., Legoux J.G., Lima R.S., Engineering HVOF-sprayed Cr3C2-NiCr coatings: The effect of particle morphology and spraying parameters on the microstructure, properties, and high temperature wear performance, Journal of Thermal Spray Technology, 22 (2013) 280-289.

11. Myalska H., Szymański K., Moskal G., Microstructure and selected properties of WC-Co-Cr coatings deposited by high velocity thermal spray processes, Solid State Phenomena, 246 (2016) 117-122.

12. Melendez N.M., McDonald A.G., Development of WC-based metal matrix composite coatings using low-pressure cold gas dynamic spraying, Surface and Coatings Technology, 214 (2013) 101-109. 
13. Winnicki M., Baszczuk A., Jasiorski M., Małachowska A., corrosion resistance of copper coatings deposited by cold spraying, Journal of Thermal Spray Technology, 26 (2017) 19351946.

14. Tomków J., Czupryński A., Fydrych D., The abrasive wear resistance of coatings manufactured on high-strength low-alloy (HSLA) offshore steel in wet welding conditions, Coatings, 10 (2020) 219.

15. Gunther K., Bergmann J.P., Suchodoll D., Hot wire-assisted gas metal arc welding of hypereutectic $\mathrm{FeCrC}$ hardfacing alloys: Microstructure and wear properties, Surface and Coatings Technology, 334 (2018) 420-428.

16. Xinhong W., Lin C., Min Z., Zengda Z., Fabrication of multiple carbide particles reinforced Febased surface hardfacing layer produced by gas tungsten arc welding process, Surface and Coatings Technology, 203 (2009) 976-980.

17. Tsai H.L., Tarng Y.S., Tseng C.M., Optimisation of submerged arc welding process parameters in hardfacing, International Journal of Advanced Manufacturing Technology, 12 (1996) 402-406.

18. Goswami G.L., Kumari S., Galun R., Mordike B.L., Laser cladding of $\mathrm{Ni}$ - Mo alloys for hardfacing applications, Lasers in Engineering, 13 (2003) 1-12.

19. Lisiecki A., Ślizak D., Kukofka A., Laser cladding of co-based metallic powder at cryogenic conditions, Journal of Achievements in Materials and Manufacturing Engineering, 95 (2019) 2031 .

20. Gnyusov S.F., Ignatov A.A., Durakov V.G., Tarasov S.Y., The effect of thermal cycling by electron-beam surfacing on structure and wear resistance of deposited M2 steel, Applied Surface Science, 263 (2012) 215-222.

21. Alhattab A.A.M., Dilawary S.A.A., Motallebzadeh A., Arisoy C.F., Cimenoglu H., Effect of electron beam surface melting on the microstructure and wear behavior of Stellite 12 hardfacing, Industrial Lubrication and Tribology, 71 (2019) 636-641.

22. Jeremic L., Dordevic B., Sedmak S., Sedmak A., Rakin M., Arandelovic M., Effect of plasma hardfacing and carbides presence on the occurrence of cracks and microcracks, Structural Integrity and Life, 18 (2018) 99-103.

23. Veinthal R., Sergejev F., Zikin A., Tarbe R., Hornung J., Abrasive impact wear and surface fatigue wear behaviour of Fe-Cr-C PTA overlays, Wear, 301 (2013) 102-108.

24. Rohan P., Boxanova M., Zhang L., Kramar T., Lukac F., High speed steel deposited by pulsed PTA - frequency influence, Proceedings to International Thermal Spray Conference, Dusseldorf, Germany (2017).

25. Zakin A., Hussainova I., Katsich C., Badisch E., Tomastik C., Advanced chromium carbide-based hardfacings, Surface and Coatings Technology, 206 (2012) 4270-4278.

26. Boulos M.I., Fauchais P., Pfender E., Plasma torches for cutting, welding and PTA coatings, in: Handbook of Thermal Plasmas, Springer Nature Switzerland (2015).

27. Skowrońska B., Sokołowski W., Rostamian R., Structural investigation of the Plasma Transferred Arc hardfaced glass mold after operation, Welding Technology Review, 92(3) (2020) 55-65.

28. Bober M., Senkara J., Comparative tests of plasma-surfaced nickel layers with chromium and titanium carbides, Welding International, 30(2) (2016) 107-111.

29. Jitai N., Wei G., Mianhuan G., Shixiong L., Plasma application in thermal processing of materials, Vacuum, 65 (2002) 263-266.

30. Mendez P.F., Barnes N., Bell K., Borle S.D., Gajapathi S.S., Guest S.D., Izadi H., Gol A.K., Wood G., Welding processes for wear resistant overlays, Journal of Manufacturing Processes, 16 (2014) 4-25. 
31. Deuis R.L., Yellup J.M., Subramanian C., Metal-matrix composite coatings by PTA surfacing, Composites Science and Technology, 58 (1998) 299-309.

32. Gurumoorthy K., Kamaraj M., Prasad Rao K., Sambasiva Rao A., Venugopal S., Microstructural aspects of plasma transferred arc surfaced Ni-based hardfacing alloy, Materials Science and Engineering A, 456 (2007) 11-19.

33. Hou Q.Y., Microstructure and wear resistance of steel matrix composite coating reinforced by multiple ceramic particulates using SHS reaction of Al-TiO2-B2O3 system during plasma transferred arc overlay welding, Surface and Coatings Technology, 226 (2013) 113-122.

34. Chattopadhyay R., Advanced thermally assisted surface engineering processes, Kluwer Academic Publishers (2004).

35. Lakshminarayanan A.K., Balasubramanian V., Varahamoorthy R., Babu S., Predicting the dilution of plasma transferred arc hardfacing of stellite on carbon steel using response surface methodology, Metals and Materials International, 14 (2008) 779-789.

36. Branagan D.J., Marshall M.C., Meacham B.E., High toughness high hardness iron based PTAW weld materials, Materials Science and Engineering A, 428 (2006) 116-123.

37. Just C., Badisch E., Wosik J., Influence of welding current on carbide/matrix interface properties in MMCs, Journal of Materials Processing Technology, 210 (2010) 408-414.

38. Huang Z., Hou Q., Wang P., Microstructure and properties of $\mathrm{Cr}_{3} \mathrm{C}_{2}$-modified nickel based alloy coating deposited by plasma transferred arc process. Surface and Coatings Technology 202 (2008) 2993-2999.

39. Flores J.F., Neville A., Kapur N., Gnanavelu A., An experimental study of the erosion corrosion behavior of plasma transferred arc MMCs, Wear 267 (2009) 213-222.

40. Kesavan D., Kamaraj M., The microstructure and high temperature wear performance of a nickel base hardfaced coating, Surface and Coatings Technology, 204 (2010) 4034-4043.

41. Skarvelis P., Papadimitriou G.D., Plasma transferred arc composite coatings with self lubricating properties, based on $\mathrm{Fe}$ and Ti sulfides: microstructure and tribological behaviour, Surface and Coatings Technology, 203 (2009) 1385-1394.

42. Klimpel A., Dobrzański L., Lisiecki A., Janicki D., The study of the technology of laser and plasma surfacing of engine valves face made of X40CrSiMo10-2 steel using cobalt-based powders, Journal of Materials Processing Technology, 175 (2006) 251-256.

43. Smoleńska H., Kończewicz W., Łabanowski J., Marine engine valves plasma hard-facing regeneration, Welding Technology Review, 83 (2011) 73-78.

44. Szala M., Hejwowski T., Lenart I., Cavitation erosion resistance on Ni-Co based coatings, Advances in Science and Technology Research Journal, 8 (2014) 36-42.

45. Górka J., Czupryński A., Kik T. Melcer M., Industrial applications of powder plasma transferred arc welding, Welding Technology Review, 83 (2011) 87-94.

46. Kik T., Moravec, J., Nováková, I., New method of processing heat treatment experiments with numerical simulation support, IOP Conference Series: Materials Science and Engineering, 227 (2017) 012069.

47. Sajek, A., Application of FEM simulation method in area of the dynamics of cooling AHSS steel with a complex hybrid welding process, Welding in the World, 63 (2019) 1065-1073.

48. Kik T., Moravec, J., Nováková, I., Numerical simulations of X22CrMoV12-1 steel multilayer welding, Archives of Metallurgy and Materials, 64 (2019) 1441-1448.

49. Kik T., Computational techniques in numerical simulations of arc and laser welding processes, Materials, 13(3) (2020) 608. 
50. Mician, M., Harmaniak, D., Novy, F., Winczek, J., Moravec, J., Trsko, L., Effect of the t8/5 cooling time on the properties of S960MC steel in the HAZ of welded joints evaluated by thermal physical simulation, Metals, 10(2) (2020) 229.

51. Kik T., Moravec, J., Nováková, I., Application of numerical simulations on 10GN2MFA steel multilayer welding, in: Dynamical systems in applications, Awrejcewicz J. (ed.), Springer Proceedings in Mathematics and Statistics, 249 (2018).

52. Bini R., Monno M, Boulus M.I., Numerical and experimental study of transferred arcs in argon, Journal of Physics D: Applied Physics, 39 (2006) 3253-3266.

53. Wang H., Chen X., Numerical modelling if the high-intensity transferred arc with a water-cooled constrictor tube, Plasma Science and Technology, 7 (2005) 3051-3056.

54. Largo F., Gonzalez J.J., Freton P., Gleizes A., A numerical modelling of an electric arc and its interaction with the anode: Part I. The two-dimensional model, Journal of Physics D: Applied Physics, 37 (2004) 883-897.

55. Bini R., Monno, Boulus M.I., Effect of cathode nozzle geometry and process parameters on the energy distribution for an argon transferred arc, Plasma Chemistry and Plasma Processing, 27 (2007) 359-380.

56. Wilden J., Bergmann J.P., Frank H., Plasma transferred arc welding - modelling and experimental optimization, Journal of Thermal Spray Technology, 15 (2006) 779-784.

57. Kumari P., Singh R.P., Development of mathematical models for prediction of weld bead geometry of hardfacing steel, International Journal of Applied Engineering Research, 10 (2015) 38509-38525.

58. Sawant M.S., Jain N.K., Nikam S.H., Theoretical modeling and finite element simulation of dilution in micro-plasma transferred arc additive manufacturing of metallic materials, International Journal of Mechanical Sciences, 164 (2019) 105166.

59. Fekih Ahmed W., Bonnefoy H., Levesque A., Crequy S., Lodini A., Thermal fatigue study of hardfaced hot forging tool using numerical analysis and residual stress evaluation, Materials Science Forum, 681 (2011) 449-454.

60. Punitharani K., Murugan N., Sivagami S.M., Finite element analysis of residual stresses and distortion in hard faced gate valve, Journal of Scientific and Industrial Research, 69 (2010) 129134.

61. Nikam S.G., Jain N.K., Three-dimensional thermal analysis of multi-layer metallic deposition by micro-plasma transferred arc process using finite element simulation, Journal of Materials Processing Technology, 249 (2017) 264-273.

62. DuMola R.J., Heath G.R., New developments in the plasma transferred arc process, in: Berndt C.C. (ed.), Proceedings of the UTSC, Indianapolis, IN, ASM International, Materials Park, OH (1997) 427-434.

63. Bouaifi B., Bartzsch J., Gebert A., Heinze H., Investigations into plasma arc surfacing of wearresistant hard-material layers using vanadium carbides, Welding and Cutting, 49 (1997) 54-56.

64. Dilthey U., Kabatnik L., Central powder feed in the plasma arc powder surfacing process, Welding and Cutting, 12 (1998) E230-771.

65. Bach F.W., Zühlsdorf J., Plasma powder welding under raised pressure environment, in: Lugscheider E. and Kammer P. (eds.), Proceedings of the UTSC, DVS, Düsseldorf (1999) 757760.

66. Bouaifi B., Ait-Mekideche A., Gebert A., Wocilka D., Utilisation of high-temperature plasmas containing nitrogen for reactive coating by means of plasma-arc weld surfacing, Welding and Cutting, 53 (2001) E170-E173. 
67. Wang W., Qian S.Q., Zhou X.Y., Microstructure and properties of TiN/Ni composite coating prepared by plasma transferred arc scanning process, Transactions of Nonferrous Metals Society of China, 19 (2009) 1180-1184.

68. Shubert G.C., Welding apparatus method for depositing wear surfacing material and a substrate having a weld bead thereon. US Patent 4,689,463 (1987).

69. Saltzman G., Sahoo P., Applications of plasma arc weld surfacing in turbine engines, in: Berndt C.C. (ed.) Proceedings of the fourth national thermal spray conference, Pittsburgh, ASM International, Materials Park, (1991) 541-548.

70. D’Oliveira C.M., Paredes R.S., Santos R.L., Pulsed current plasma transferred arc hardfacing, Journal of Materials Processing Technology 171 (2006) 167-174.

71. Ebert L., Thurner S., Neyka S., Influencing the distribution of reinforcing particles in plasma transfer arc welding, Materialwissenschaft und Werkstofftechnik, 40 (2009) 878-881.

72. Lugscheider E., Langer G., Schlimbach K., Dilthey U., Kabatnik L., Possibilites for improving wear-properties of aluminum-alloys by plasma powder welding process, in: Lugscheider E., Kammer P. (eds.), Proceedings of the united thermal spray conference, Dusseldorf, Germany. DVS, Dusseldorf, Germany (1999) 410-413.

73. Dilthey U., Kondapalli S., Balashov B., Riedel F., Improving wear resistance of aluminium alloys by developing FTC and TiC based composite coatings using plasma powder arc welding process, Surface Engineering, 24 (2008) 75-80.

74. Leylavergne M., Chartier T., Denoirjean A., Grimaud A., Abelard P., Fauchais P., Cast iron substrates reclamation by tape casting of $\mathrm{NiCu}$ treated by plasma transferred arc: optimization of the tape and its plasma treatment, Thin Solid Films, 391 (2001) 1-10.

75. Proner A., Ducos M., Dacquet J.P., Process for coating of hardfacing a part by means of a plasma tranferred arc. US Patent US 5,624,717 (1997).

76. Reisgen U., Balashov B., Stein L., Geffers C., Nanophase hardfacing new possibilities for functional surfaces, Materials Science Forum, 638-642 (2010) 870-875.

77. Hinners H., Konyashin I., Ries B., Petrzhik M., Levashov E.A., Park D., Weirich T., Mayer J., Mazilkin A.A., Novel hardmetals with nano-grain reinforced binder for hard-facings, International Journal of Refractory Metals and Hard Materials, 67 (2017) 98-104.

78. Alvarez-Vera M., Torres-Mendez J.C., Hdz-Garcia H.M., Munoz-Arroyo R., Mtz-Enriquez A.I., Acevedo- Davila J.L., Hernandez-Rodriguez M.A.I., Wear resistance of TiN or AlTiN nanostructured Ni-based hardfacing by PTA under pin on disc test, Wear, 426-427 (2019) 15841593.

79. Hou Q., Huang Z., Wang J.T., Influence of nano- $\mathrm{Al}_{2} \mathrm{O}_{3}$ particles on the microstructure and wear resistance of nickel-based alloy coating deposited by plasma transferred arc overlay welding, Surface and Coatings Technology, 205 (2009) 2806-2812.

80. Albertli E.A., Bueno B.M.P., D’Oliveira A.S.C.M., Additive manufacturing using plasma transferred arc, The International Journal of Advanced Manufacturing Technology, 83 (2016) 1861-1871.

81. Hoefer K., Mayr P., Additive manufacturing of titanium parts using 3D plasma metal deposition, Materials Science Forum, 941 (2018) 2137-2141.

82. Mercado Rojas J.G., Wolfe T., Fleck B.A., Quershi A.J., Plasma transferred arc additive manufacturing of nickel metal matrix composites, Manufacturing Letters, 18 (2018) 31-34.

83. Perez-Soriano E.M., Ariza E., Arevalo C., Montealegre-Melendez I., Kitzmantel M., Neubauer E., Processing by additive manufacturing based on plasma transferred arc of hastelloy in air and argon atmosphere, Metals, 10 (2020) 200. 
84. Jhavar S., Jain N.K., Paul C.B., Development of micro-plasma transferred arc wire deposition process for additive layer manufacturing application, Journal of Materials Processing Technology, 214 (2014) 1102-1110.

85. Wang H., Jiang W., Valant M., Kovacevic R., Microplasma powder deposition as a new solid freeform fabrication process, Proceedings of the Institution of Mechanical Engineers Part B Journal of Engineering Manufacture, 217 (2003) 1641-1650.

86. Hallen H., Mathesius H., Ait-Mekideche A., Hettiger F., Morkramer U., Lugscheider E., New applications for high power PTA surfacing in the steel industry, in: Berndt C.C. (ed.) Proceedings of the international thermal spray conference and exposition, Orlando, FL, ASM International, Materials Park, OH (1992) 899-902.

87. Hou Q.Y., He Y.Z., Zhang Q.A., Gao J.S., Influence of molybdenum on the microstructure and wear resistance of nickel-based alloy coating obtained by plasma transferred arc process, Materials and Design, 28 (2007) 1982-1987.

88. Wang X.B., Cai L.J., Yang Z.H., Xiao C., Xu L.F., Selection of covering materials for synthesising fabrication of TiB2 based coating with PTA process, Surface Engineering, 25 (2009) 470-475.

89. Liu Y.F., Liu X.B., Xua X.Y., Yang S.Z., Microstructure and dry sliding wear behavior of Fe2TiSi/-Fe/Ti5Si3, Surface and Coatings Technology, 205 (2010) 814-819.

90. Farag S., Konyashin I., Ries B., The influence of grain growth inhibitors on the microstructure and properties of submicron, ultrafine and nano-structured hardmetals - A review, International Journal of Refractory Metals and Hard Materials, 77 (2018) 12-30.

91. Acevedo-Davila J.L., Munoz-Arroyo R., Hdz-Garcia H.M., Martinez-Enriquez A.I., AlvarezVera M., Hernandez-Garcia F.A., Cobalt-based PTA coatings, effects of addition of TiC nanoparticles, Vacuum, 143 (2017) 14-22. 